\title{
Mechanisms of penetration in polyethylene reinforced cross-ply laminates
}

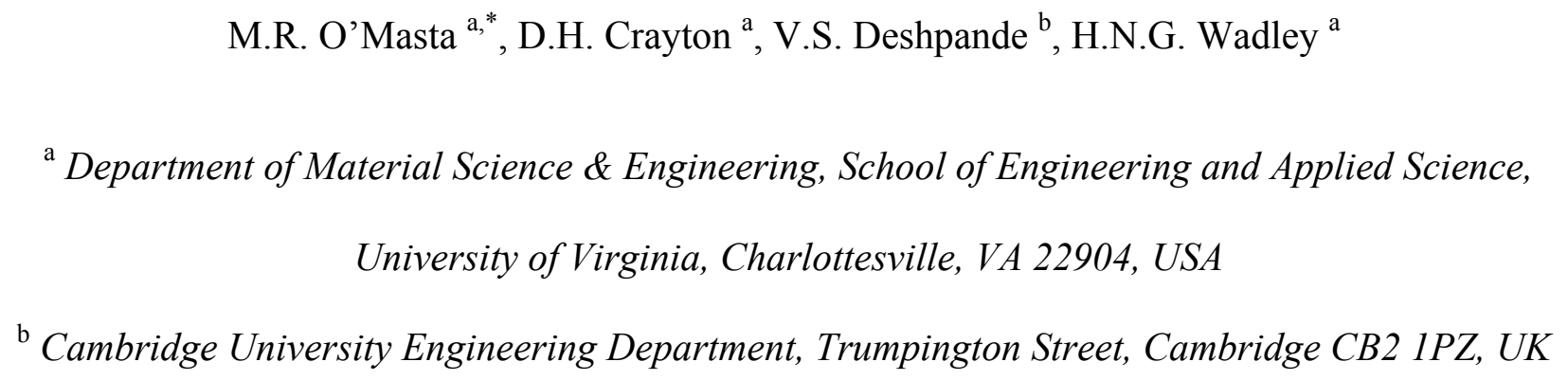

a Department of Material Science \& Engineering, School of Engineering and Applied Science, University of Virginia, Charlottesville, VA 22904, USA

${ }^{\mathrm{b}}$ Cambridge University Engineering Department, Trumpington Street, Cambridge CB2 1PZ, UK

\section{Abstract}

The mechanisms of progressive penetration for two ultrahigh molecular weight

11 polyethylene (UHMWPE) reinforced laminates have been investigated. One used an UHMWPE

12 fiber reinforcement while the other utilized molecularly aligned tape. Both materials had similar

13 out of plane compressive strengths, but the fiber system had a $40 \%$ higher in plane tensile

14 strength than the tape. Laminated, $6 \mathrm{~mm}$ thick plates with a $\left[0^{\circ} / 90^{\circ}\right]$ ply architecture were

15 impacted by a $12.7 \mathrm{~mm}$ diameter sphere under conditions that either allowed out of plane plate

16 deflection or eliminated this deflection by rear support of the target. The depth of penetration,

17 and the ballistic limit in the rear-supported tests was identical for the two materials, and

18 proceeded by progressive ply failure. However, tests in the edge clamped condition resulted in a

19 substantially higher penetration resistance, especially for the higher tensile strength fiber-

20 reinforced material. Edge clamped testing of a bilayer target, where the front third was

21 comprised of the tape material and the remainder comprised fiber reinforced laminate, had the

22 same ballistic limit as a target comprised of only the higher ply tensile strength fiber reinforced

23 material. Penetration in both test support conditions was discovered to occur by tensile ply

24 rupture under the projectile, consistent with a recently proposed mechanism for converting out of

25 plane compression to in plane ply tension. Lateral displacement of plies was also observed near 
26 the sides of impact craters in both materials, indicating the existence of a second mechanism

27 impeding penetration of the spherical shaped projectile.

28

29 Keywords: ballistics; polymeric composites; penetration mechanisms; hybrid laminates

30

31

$32{ }^{*}$ Corresponding author.

33 E-mail address: mro4h@virginia.edu (M.R. O’Masta).

34 


\section{Introduction}

It is well known that composite laminates comprising high tensile strength polymeric

37 reinforcements and compliant polymer matrices possess very high ballistic penetration

38 resistances when configured in a $\left[0^{\circ} / 90^{\circ}\right]$ cross-ply architecture $[1,2]$. However, the mechanisms

39 by which an impacting projectiles momentum and kinetic energy are dissipated during

40 penetration are much less well understood, and are the focus of the study reported here. The

41 response to transverse (out of plane) impact of a thin laminate has been analyzed by analogy with

42 that of a single fiber [3-5]. The central impact of a single, end clamped fiber generates strain

43 pulses that propagate away from the impact site. The fastest of these elastic disturbances travels

44 along the fibers at the fibers longitudinal wave speed,

$$
c_{L}=\sqrt{(\lambda+2 \mu) / \rho}
$$

Eq. 1

where $\lambda$ and $\mu$ are the Lamé constants and $\rho$ the density of the fiber [6]. A shear wave

48 with a lower velocity $c_{H}=\sqrt{\mu / \rho}$ travels behind the longitudinal disturbance, enabling the fiber

49 to undergo transverse deflection in the direction of projectile motion. The analogous wave speeds

50 in a composite laminate are governed by the stiffness constants of the laminate, and are therefore

51 orientation dependent [7]. For a $\left[0^{\circ} / 90^{\circ}\right]$ cross-ply lay-up, they are highest in the fiber directions,

52 giving rise to a 'pyramid shaped' transverse deflection envelope during impact, Fig. 1(a), whose

53 base width expands with time.

Using dimensional analysis, Cunniff [1] showed that the ballistic limit of a fiber scales

56 with the product of its longitudinal wave speed and the strain energy per unit mass needed to fail

57 a fiber in tension. This combination of material properties gives rise to a Cuniff velocity: 
where $\mathrm{E}_{f}, \boldsymbol{\sigma}_{f}$ and $\varepsilon_{f}$ are the Young's modulus, tensile strength and failure strain of a linear

61 elastic fiber and $\rho$ its density. A comprehensive compilation of the predicted Cunniff velocities

62 of most high performance fibers has been given in reference [8] and indicates that ultra-high

63 molecular weight polyethylene (UHMWPE) fibers should have a very high ballistic limit.

64 However, this approach provides little insight into the mechanisms of penetration of $\left[0^{\circ} / 90^{\circ}\right]$

65 laminated composites constructed from such fibers.

Phoenix and Porwall [4] analyzed the deflection of an impacted laminate in the thin membrane limit where the transverse deflection of the laminate was governed by (tensile)

69 membrane stresses supported by the fibers within the laminate. In this limit, the fiber stress is

70 independent of depth, and laminate perforation occurs when the membrane stress attains the ply

71 tensile strength. All else being equal, laminates with higher ply tensile strengths will have a

72 greater resistance to perforation. While the ballistic limit predictions of the Phoenix and Porwall

73 membrane stretching model are consistent with the dimensional analysis of Cunniff [1], failure

74 was treated as a binary process; the laminate was either undamaged or fully penetrated by an

75 impacting projectile. No partial penetration is permitted by such an analysis. However, numerous

76 experiments have shown that UHWMPE fiber reinforced laminates fail progressively, with a

77 depth of penetration that increases with impact velocity [8-13]. 
A study by Heisserer [11] using HB26 ${ }^{1}$ grade Dyneema ${ }^{\circledR}$, showed the depth of

80 penetration by a hard spherical projectile increased linearly with projectile kinetic energy. Recent

81 studies by Karthikeyan and Russell [13] using a spherical projectile and by Nguyen et al. [14]

82 using fragment simulating projectiles (FSP), confirmed the existence of progressive penetration

83 before the laminates ballistic limit was attained. All these studies indicate the penetration of

84 these materials occurs in two stages schematically illustrated in Fig. 1(b). The first "progressive"

85 stage of penetration occurs early during the impact process. It is accompanied by minimal

86 transverse deflection of the failed plies. The second corresponds to the out of plane deflection of

87 the unpenetrated remainder of the laminate by a membrane stretching mechanism which results

88 in fiber pull-in in the $0^{\circ}$ and $90^{\circ}$ fiber directions (converting a square sided panel into a pin

89 cushion shape). Karthikeyan and Russell [13] estimated the second stage dissipated $\sim 6.5$ times

90 more kinetic energy per perforated ply than that of the progressive penetration stage. Efforts to

91 impede the progressive mode of penetration, forcing failure by the second membrane-stretching

92 mode are therefore likely to result in substantial improvements to the ballistic resistance of these

93 composite materials.

There are many mechanisms by which materials can be progressively penetrated by a

96 projectile. For example, penetration can occur by shear plugging, and experimental evidence for

97 this has been widely reported for carbon (CRFP) and glass (GRRP) fiber reinforced polymer

98 composites constructed with impact resistant polymeric matrices [15-20]. This mechanism can

99 be activated when the shear stress (normal to the fiber directions) created by the projectile

100 reaches the dynamic shear strength of the laminate. A plug of material of roughly the diameter of

101 contact surface is then formed beneath the projectile, Fig. 1(c). However, the literature currently

\footnotetext{
${ }^{1} \mathrm{~A}\left[0^{\circ} / 90^{\circ}\right]$ cross-ply laminate consisting of 83 vol\% UHMWPE SK76 fibers in a polyurethane matrix.
} 
102 offers no observational evidence for the formation of such a shear plug in UHWMPE fiber

103 reinforced composites. These materials have a very high fracture resistance under transverse

104 shear loading because the fibers are very flexible (do not fracture upon bending) and their tensile

105 strength is very high. Furthermore, He and Hutchinson [21] and more recently Noselli et al. [22]

106 have shown that delamination at interply interfaces, rather than ply cracking, dominates the

107 response of laminates made from highly anisotropic plies.

108

109 Recent experiments suggest an alternative mechanism governs the progressive phase of

110 penetration. Indirect evidence from impact experiments indicated that reduction of the pressure

111 imposed by a projectile on a laminate improves the resistance to progressive penetration

$112[8,12,23,24]$. Furthermore, quasi-static studies have shown that $\left[0^{\circ} / 90^{\circ}\right]$ laminates uniformly

113 compressed normal to the plane of the fibers fail by tensile fiber (and ply) failure [25-27].

114 Atwood et al. [25] showed how this counter-intuitive phenomenon can arise if the plastic Poisson

115 expansion of a compressed ply transverse to the fiber direction is much greater than that parallel

116 to the fibers, Fig. 1(e). A transfer of stress occurs from an expanding pair of $0^{\circ}$ plies to the $90^{\circ}$

117 ply located between them occurs. This shear lag loading mechanism then places the $90^{\circ}$ ply in

118 tension in the fiber direction (while the expansion of the $90^{\circ}$ ply also loads the $0^{\circ}$ ply in tension).

119 As compression of the laminate progresses, the tensile strength of the ply is eventually reached

120 and sudden fracture occurs. The compressive strength therefore directly depends upon the ply

121 tensile strength and inter-laminar shear strength $[25,26]$.

122

123 Other mechanisms could also be activated. For example, under some situations lateral

124 displacement of material away from the nose of the projectile, analogous to ductile hole 
125 enlargement [28,29], could occur. In the ductile materials in which hole enlargement occurs, the

126 radial stress from the penetrating projectile plastically displaces material, leaving a cavity in the

127 wake of the projectile. This 'slip' of material around a projectile has been frequently observed in

128 dry woven composites made from UHWMPE and aramid fibers [30], but is retarded if the fibers

129 are embedded in a resin with high shear strength resistance.

131 One way to test the significance of the indirect tension progressive penetration

132 mechanism is to construct laminates from materials with similar out-of-plane compressive

133 strengths, but with different tensile strengths. It is noted that UHMWPE tapes [31,32],

134 manufactured under the trade names Tensylon ${ }^{\circledR}$ by DuPont and more recently grade BT10

135 Dyneema ${ }^{\circledR}$ by DSM, offer a means to compare laminates with similar compressive strengths but

136 with different ply tensile strengths. Even though the tensile strength of the tape materials is

137 substantially less than that of the fiber-based materials, their out of plane compressive strengths

138 are similar to the fiber based grades of these materials. Additional insights can be gained by

139 subjecting panels of the two materials to impacts under conditions that either permit or inhibit

140 the membrane stretching response. A simple means for this is to place the laminate on a solid

141 foundation so it cannot be displaced in the out-of-plane direction required to activate membrane

142 stretching [9]. The study presented here shows that the depth of (progressive) penetration and

143 ballistic limit of the fiber and tape-based laminates are similar when membrane stretching is

144 prevented. The study then investigates the edge clamped impact response of the two laminates,

145 and a bilayer target comprised of both materials, and reveals the presence of the same

146 progressive penetration mode observed in the rear supported condition. 


\section{Materials and properties}

The study was conducted using two laminated grades of UHWMPE Dyneema ${ }^{\circledR}$ (DSM,

150 The Netherlands), Table 1 . The grade HB50 laminates comprised a $\left[0^{\circ} / 90^{\circ}\right]$ cross-ply lay-up of

$15160 \mu \mathrm{m}$ thick plies of unidirectional grade SK76 Dyneema ${ }^{\circledR}$ fiber in a rubber-modified resin that

152 accounted for 17 wt. \% of the composite, Fig. 2(a). The properties of the HB50 laminate and its

153 SK76 fiber have been extensively studied [12,23,26,33]. The second material, grade BT10 tape,

154 consisted of $100 \mathrm{~mm}$ wide by $42 \mu \mathrm{m}$ thick strips of UHWMPE solid-state tape. The strips were

155 plain weave woven with a $200 \mathrm{~mm}$ periodicity, Fig. 3(a). Both materials were received as 4 ply

156 thick 'pre-pregs' that could be consolidated into a laminate at a temperature of $127^{\circ} \mathrm{C}$ for $\mathrm{HB} 50$

157 and $130^{\circ} \mathrm{C}$ for BT10 using a pressure of $20.6 \mathrm{MPa}$. Prior to consolidation of the BT10 grade, the

158 lightly adhered woven strips were first separated and then laminated to create a non-woven

$159\left[0^{\circ} / 90^{\circ}\right]$ cross-ply lay-up, Fig. 3. This modified composite is subsequently referred to as BT10m,

160 Fig. 2(b), while the term BT10 will refer to the as-received woven pre-preg.

Table 1. Laminate architecture and mechanical properties.

\begin{tabular}{l|cc}
\hline & HB50 & BT10m \\
\hline Reinforcement type & Fiber & Solid-state tape \\
$\begin{array}{l}\text { Reinforcement grade } \\
\text { Resin }\end{array}$ & SK76 & BT10 \\
Fiber diameter/ tape thickness, & SISTC & N/A \\
$t(\mu \mathrm{m})$ & 17 & 42 \\
$\begin{array}{l}\text { Ply thickness, } h(\mu \mathrm{m}) \\
\begin{array}{l}\text { Longitudinal ply modulus, } E_{f} \\
(\mathrm{GPa})\end{array}\end{array}$ & 60 & 42 \\
$\begin{array}{l}\text { Ply tensile strength, } \sigma_{f}(\mathrm{GPa}) \\
\begin{array}{l}\text { Inter-laminar shear strength, } \tau_{0} \\
(\mathrm{MPa})\end{array}\end{array}$ & 0.35 & 100 \\
Resin abbreviation: styrene-isoprene-styrene triblock copolymer (SISTC)
\end{tabular}

163

* Resin abbreviation: styrene-isoprene-styrene triblock copolymer (SISTC)

164 


\subsection{Mechanical properties}

\subsubsection{Tension and shear}

Measurement of the tensile and shear strengths of the composites followed the procedures described by O'Masta et al. [26]. The unidirectional ply tensile strength was calculated from laminate tensile tests (taken to be twice the measured laminate's strength) since Russell et al. [33] revealed fiber misalignment and waviness and changes in fiber morphology reduce the ply strength compared to that expected from single fiber tests. The tensile tests used a $\left[0^{\circ} / 90^{\circ}\right]_{4}$, dogbone shaped coupon under a gripping pressure of $50 \mathrm{MPa}$ and loaded at a nominal tensile strain rate of $10^{-3} \mathrm{~s}^{-1}$. The shear tests utilized a $\left[0^{\circ} / 90^{\circ}\right]_{40}, 20 \mathrm{~mm}$ wide, double-notch specimen, with a $20 \mathrm{~mm}$ gauge length, loaded at a rate of $1 \mathrm{~mm} \mathrm{~min}^{-1}$. Table 1 summarizes the measured tensile and shear strengths for the two materials. The measurements for HB50 compare well with values published elsewhere [12], and confirm that the HB50 laminate has a 40\% higher tensile strength than BT10, but only a tenth of the BT10 laminates shear strength.

\subsubsection{Uniform compression strength}

When cross-ply $\left[0^{\circ} / 90^{\circ}\right]$ laminates are placed under out of plane uniform compression, the anisotropic expansion between neighboring plies creates internal tensile stresses by a shearlag mechanism [25]. The stress increases from zero at the edge of a sample to a constant stress over the shear lag length (inset of Fig. 4(b)). Therefore, the effective compressive strength increases with the in-plane length of the sample, $L$, approaching a plateau strength governed by the ply tensile strength as the shear lag length becomes small compared to that of the sample. However, the plateau strength of thin laminates can be reduced by the presence of missing fiber defects in fiber reinforced Dyneema ${ }^{\circledR}[24]$. 
Six $1 \mathrm{~mm}$ thick samples (consisting of 16 HB50 plies and 24 BT10m plies) with $L=6$ to

$18915 \mathrm{~mm}$ and two others with $L=20$ and $25 \mathrm{~mm}$ that were 240 plies thick were prepared from both

190 materials. Representative compressive stress-strain curves of HB50 and BT10m samples are

191 plotted in Fig. 4(a) together with their tangent modulus. The stress for both grades monotonically

192 increased with strain, with the tangent modulus of the BT10m sample being approximately twice

193 that of HB50. The samples catastrophically failed at a peak strength, $\sigma_{c}$. The compressive

194 strength, obtained by averaging test results from five specimens of each material and sample

195 length combination, are plotted in Fig. 4(b). The strength of both materials monotonically

196 increased with $L$ as expected. However, the BT10m laminate had a higher compressive strength

197 than HB50 despite its lower ply tensile strength. This is attributed in part to a smaller shear lag

198 length for BT10m and to less efficient conversion of compressive stress into tension of the

199 reinforcement, as a consequence of the low plastic shear resistance of HB50 [25]. This

200 (fortuitous) difference in response to compression loading results in the two materials having a

201 similar compressive strengths in the large $L$-limit (a $6 \%$ difference at $L=25 \mathrm{~mm}$ ), but markedly

202 different tensile strengths.

\subsubsection{Punch penetration}

The quasi-static punch resistance of each laminate was investigated with the sphere used 205 subsequently for the impact study. A hardened, 52100 chrome-steel sphere (CCR Products LLC, 206 West Hartford, CT), measuring $12.7 \mathrm{~mm}$ in diameter, centrally loaded a $100 \mathrm{~mm} \times 100 \mathrm{~mm} \times 6$ 207 mm laminated panel placed on a hardened, A2 steel plate, at a displacement rate of $20 \mathrm{~mm} \mathrm{~min}^{-1}$, 208 Fig. 5 (a). For HB50, the load, $F$, monotonically increased with depth of penetration, $\alpha$, reaching 209 a peak load of $25 \mathrm{kN}$, Fig. 5(a). Attainment of the peak load coincided with a highly unstable 
210 failure event, similar to that observed during uniform compression, and was accompanied by a

211 large drop in load. This load-to-failure sequence was repeated with continued penetration. Figure

212 5(a) shows that the BT10m panels exhibited a similar response to penetration and failed at the

213 same peak load, consistent with the uniform compression study. Cross-sectioned HB50 and

214 BT10m samples after $2 \mathrm{~mm}$ of penetration are shown in Fig. 5(b) and (c), respectively.

215

216 3. Impact study

217 The penetration behavior during impact of both HB50 and BT10m grade laminates and 218 hybrid samples made up of both grades was investigated using the hardened steel sphere. Some

219 tests were performed with the laminates back-supported on a hard foundation while others

220 utilized edge clamped boundaries that allowed samples to undergo out of plane (transverse)

221 deflection.

\subsection{Sample fabrication}

Preliminary studies indicated the impact of a rear-supported laminate engaged a small

224 area of the target, whereas the entire laminate was engaged in deformation during edge-clamped

225 testing. The rear-supported targets were therefore fabricated to an in-plane size of $100 \mathrm{~mm} \times 100$

$226 \mathrm{~mm}$, while the edge clamped targets were $200 \mathrm{~mm} \times 200 \mathrm{~mm}$, Fig. 6 . For both target types, the

227 plates were hot-consolidated to a nominal thickness of $6 \mathrm{~mm}$ (an areal density of $5.82 \mathrm{~kg} \mathrm{~m}^{-2}$ ),

228 which required a lay-up of $\left[0^{\circ} / 90^{\circ}\right]_{50}$ for $\mathrm{HB} 50$ and $\left[0^{\circ} / 90^{\circ}\right]_{72}$ for BT10m. A third, hybrid sample

229 was fabricated by replacing the front (impacted side) third of an HB50 sample with BT10m

230 resulting in a $\left[\left(0^{\circ} / 90^{\circ}\right)_{24 \mathrm{~B}} /\left(0^{\circ} / 90^{\circ}\right)_{33 \mathrm{H}}\right]$ lay-up. 
233 single $100 \mathrm{~mm}$ wide tape was unwoven from the BT10 preg, Fig 3(a). To assemble a $200 \mathrm{~mm}$

234 wide ply, a strip of tape was split into two $50 \mathrm{~mm}$ wide strips, which were then placed adjacent

235 to either side of a $100 \mathrm{~mm}$ wide strip, Fig. 3(b). The strips were held in place by dowel pins and a

236 second set of $50 / 100 / 50 \mathrm{~mm}$ strips was laid on top, but rotated $90^{\circ}$ to the first set, forming a

237 second ply. This process was repeated to assemble the $\left[0^{\circ} / 90^{\circ}\right]_{72}$ lay-up. Once consolidated, the

238 excess length of material used for alignment was removed using a band saw, Fig. 3(c). This

239 fabrication method ensured that the seams between adjacent strips were distant from the impact

240 site.

242 Prior to testing, a $5 \mathrm{~mm}$ spaced square grid pattern was drawn on the front face of all the 243 targets. The black grid was aligned with the reinforcement orientations, and its contrast against

244 the white $\left(\right.$ Dyneema $\left.^{\circledR}\right)$ target provided a visual aid for interpreting high-speed video data 245 collected during the impact process.

\section{3.2. Impact test protocol}

247 Each rear supported target was clamped to a $100 \mathrm{~mm}$ x $100 \mathrm{~mm}$ x $20 \mathrm{~mm}$, A2 steel plate

248 (hardened to $62 \mathrm{HRC}$ ) using two C-clamps at opposing corners, Fig. 6(a). Each edge clamped

249 target was gripped between two $254 \mathrm{~mm}$ x $254 \mathrm{~mm}$ x $5 \mathrm{~mm}$ steel plates, Fig. 6(b). Each steel

250 plate had a $150 \mathrm{~mm} \times 150 \mathrm{~mm}$ central hole with sixteen clearance holes for $10 \mathrm{~mm}$ bolts around

251 the periphery of the center hole. Bolts, passing through the two steel plates and the target, 252 clamped the target in place. 
255 the set-up schematically drawn in Fig. 7. The hardened, steel sphere, measuring $12.7 \mathrm{~mm}$ in

256 diameter and $8.4 \mathrm{~g}$ in weight, impacted the targets normally ( $0^{\circ}$ obliquity) and centrally. The

257 impact velocity, $V_{i}$, was calculated from the time of flight for the projectile to travel between two

258 paper break screens. A model v1610 Phantom high-speed camera (Wyane, NJ) recorded an

259 oblique view of the front of the target to observe the deformation of the outer ply. The camera

260 was set to an exposure time of $0.45 \mu$ s with an inter-frame delay of $1.52 \mu \mathrm{s}$, which required the

261 image resolution to be reduced to $128 \times 48$ pix. A second model v7 Phantom video camera,

262 recorded a side profile view of the target with an exposure time of $1.8 \mu$ s and an inter-frame

263 delay of $18.75 \mu$ s. This camera provided images for calculation of the incident and residual

264 velocity, $V_{r}$, of any projectile that perforated the edge-clamped laminates. The incident velocities

265 measured by the break screens and the high-speed camera agreed to within $2 \mathrm{~m} \mathrm{~s}^{-1}$ over the

266 velocity range tested.

267

268 The ballistic limit, $V_{b l}$, of each target type (material and gripping condition) was defined

269 as the average of the lowest impact velocity to perforate the target and the highest impact

270 velocity to penetrate, but not perforate, the target. A penetration onset velocity, $V_{0}$, was also

271 defined as the average of the lowest impact velocity to penetrate the target and the highest impact

272 velocity that did not penetrate the target. The low launch velocity limit of the gun prevented

273 identification of $V_{0}$ for the rear-supported targets, so this was obtained by extrapolation of the

274 data. 
277 partially penetrated targets. Edge clamped targets, which were larger and often contained

278 embedded projectiles, were using a voxel size of $62 \mu \mathrm{m}$. Rear supported targets, having a smaller

279 affected area and without an embedded projectile, were examined using a higher resolution,

280 Xradia (Pleasanton, CA, USA) model $\mu$ XCT-200 machine. The instrument recorded an $8.3 \mathrm{~mm}$

281 diameter sphere with a voxel size of $8.1 \mu \mathrm{m}$. Digital stitching of multiple scans provided images

282 of a larger volume. Some rear-supported targets were also sectioned to expose damage along a

283 transverse $(Y-Z)$ plane passing through the impact crater. Each sample was first embedded in

284 Ultrathin 2 Castable Epoxy (Pace Technologies Corp., Tucson, AZ), sectioned by a band-saw,

285 and finally polished using progressively higher grit $\operatorname{SiC}$ paper (240, 320, 400, 600 and 800 grit).

286 Samples were then imaged using a Nikon model D7000 camera equipped with a 105 mm Micro-

287 Nikkor lens and an extension tube.

The depth of penetration was measured for each sample and recorded as the parameter, $f$,

290 defined as the thickness of failed material divided by the initial target thickness. The thickness

291 was calculated by counting the number of plies that had failed.

\section{4. Impact results}

\section{4.1. Rear supported samples}

Nine HB50 and eight BT10m rear supported targets were impacted by a $12.7 \mathrm{~mm}$

296 diameter spherical projectile at velocities of 67 to $299 \mathrm{~m} \mathrm{~s}^{-1}$. The depth of penetration,

297 represented by the perforated laminate fraction, $f$, is plotted as a function of impact velocity, $V_{i}$, 
298 in Fig. 8(b). Both materials behaved similarly. For HB50, the depth of penetration increased

299 linearly from $f=0.22$ at the lowest impact velocity, $\left(V_{i}=75 \mathrm{~m} \mathrm{~s}^{-1}\right)$ to its ballistic limit, $V_{b l}=215$

$300 \pm 10 \mathrm{~m} \mathrm{~s}^{-1}$. BT10m exhibited the same dependence of penetration depth upon impact velocity,

301 Fig. 8(b), and had a ballistic limit that, within the experimental uncertainty, as the HB50

302 material, Table 2. The rear supported hybrid target had a similar penetration performance to

$303 \mathrm{HB} 50$ and BT10m. It is noted that extrapolation of the penetration data to $f=0$ gives a

304 penetration onset velocity of $\sim 45 \mathrm{~m} \mathrm{~s}^{-1}$ for the three material systems. of the impact site is shown in Fig. 9(a). The projectile created a circular-shaped crater in the

311 target, with failed plies defining the perimeter of the impact crater. The $90^{\circ}$ plies (the darker grey 312 shade ply whose fibers are in the $Y$-direction) that had fractured under the projectile had recoiled

313 and buckled at the side of the impact crater during rebound, leading to a bulging of the region.

314 The $0^{\circ}$ plies appear to have thickened at the side of the crater and contributed to the bulging of 315 material around the edge of the projectile impacted region. This bulge zone was about $2 \mathrm{~mm}$ in 316 width in the $X$-and $Y$-directions at the edge of the crater. The optical image shows no evidence 
317 of any ply damage beneath the impact crater, and was similar to that observed during quasi-static 318 penetration with a punch, Fig. 5(b).

Increasing the impact velocity to $149 \mathrm{~m} \mathrm{~s}^{-1}$, Fig. 9(b) resulted in a deeper and wider

321 impact crater, and a $\sim 7 \mathrm{~mm}$ wide bulge zone again containing microbuckled $90^{\circ}$ plies and

322 thickened $0^{\circ}$ plies. Because the sectioned plane in Fig. 9(b) is slightly offset from the mid-plane

323 of the impact site, the maximum depth of the impact crater was slightly wider and deeper than

324 shown. The seven plies immediately below the bottom of the impact crater have thickened (in

325 particular the $0^{\circ}$ plies whose fibers were in the $X$-direction) and had rebounded upwards towards

326 the impact crater. An out-flow of material from the impacted region into surrounding material

327 and towards the impact surface is apparent. Sections through BT10m targets after impact at

328 similar velocities revealed the same failure and deformation modes, Fig. 9(c) and (d). No

329 evidence of shear plug formation could be seen in any of the samples.

Fig. 10(a) shows a $\mu \mathrm{XCT}$ reconstructed $Y-Z$ cross-section along the impact crater mid-

332 plane of a partially penetrated HB50 target. Failed ends from $90^{\circ}$ plies are visible near the

333 bottom of the crater ${ }^{2}$. These failed plies had recoiled away from the impact crater into the

334 surrounding material forming small microbuckled folds. This lateral displacement of failed plies

335 was accompanied by delamination between the plies. Fig. 11 shows a similarly imaged BT10m

336 target after impact at a similar velocity. The failure process appears to be identical to that of the

337 HB50 material.

\footnotetext{
${ }^{2}$ Single fibers are difficult to identify given their similar density to the matrix and the voxel size of $8.1 \mu \mathrm{m}$.
} 
A magnified view of a transverse section near the bottom of the crater of the HB50 target

340 is shown in Fig. 10(b). The $90^{\circ}$ plies, whose fibers run into the page, show considerable

341 thickening from in-plane extrusion of fibers transverse to the fiber direction. Fig. 10(c) shows an

342 in-plane $(X-Y)$ cross-section through the impact crater of a failed $90^{\circ}$ ply. A $\sim 1.5$ mm wide ply

343 strip had failed, and the fractured ends had been laterally displaced $\sim 2.6 \mathrm{~mm}$ from their original

344 position. Fibers to either side of the failed portion were also laterally displaced around the impact

345 crater, with displacements accompanied by ply splitting.

The width of the failed portion of a ply, and that of the crater as a function of depth in an

348 HB50 target impacted at $143 \mathrm{~m} \mathrm{~s}^{-1}$ were also investigated. Fig. 12(a) shows a photograph of the

349 rear side of the fourth ply below the impact surface after removal from the target. The residual

350 opening was square, with a crater width defined in Fig. 12(b). This width was greater than the

351 width of the ply's failed fibers because of significant lateral ( $X$-direction) displacement of the

352 intact $Y$-direction fibers as facilitated by splitting. Fig. 12(c) shows both the width of the crater

353 and of that of failed fibers as a function of depth below the impact surface. The width of the

354 crater was well approximated by the cord length along the mid-plane of the projectile, while that

355 of the failed fibers was 2 to $3 \mathrm{~mm}$ smaller. Similar splitting of the plies was observed in the

356 BT10m targets, and indicated substantial lateral displacement of unfailed material accompanied

357 penetration in both materials.

Fig. 13(a) shows a high-speed image sequence of the oblique front view of a rear

360 supported HB50 target impact at $V_{i}=225 \mathrm{~m} \mathrm{~s}^{-1}$. A vertically displaced fiduciary marker has been

361 identified at $t=6.1 \mu \mathrm{s}$ after impact. In the following frame, the marker has been pushed away 
362 from the projectile, and ply failure is visible by $t=12.2 \mu$ s. Hence, it can be concluded that the

363 laminate failed at $9 \pm 3 \mu$ s after initiation of impact.

\section{4.2. Edge clamped targets}

365 Nine HB50, twelve BT10m and nine hybrid edge clamped targets were impacted at

366 velocities of 80 to $700 \mathrm{~m} \mathrm{~s}^{-1}$. The depth of penetration (for impacts below the panel ballistic

367 limits) and the residual velocity for fully perforated samples are shown on Fig. 8. This laminate

368 support condition resulted in substantially higher ballistic limits for both materials and the hybrid

369 laminate, Table 2. For the HB50 laminates, the start of progressive penetration was delayed,

370 from around $40 \mathrm{~m} \mathrm{~s}^{-1}$ for rear supported samples to $296 \pm 37 \mathrm{~m} \mathrm{~s}^{-1}$ for the edge clamped test. The

371 fraction of failed plies increased with impact velocity, and the laminate was completely

372 perforated at $V_{b l}=531 \pm 16 \mathrm{~m} \mathrm{~s}^{-1}$. For the BT10m laminates, progressive penetration began at an

373 impact velocity of $176 \pm 4 \mathrm{~m} \mathrm{~s}^{-1}$ and the ballistic limit was $360 \pm 33 \mathrm{~m} \mathrm{~s}^{-1}$; substantially lower

374 than HB50, Table 2. The residual velocities of the perforated targets are plotted in Fig. 8(a).

377 penetration was initially similar to that of the BT10m material located on its impact face, Fig.

378 8(b). As the impact velocity was increased above $V_{0}$, the depth of penetration ceased increasing

379 at $f \approx 1 / 3$, and a large delamination plane formed at the BT10m/HB50 interface, Fig. 14(d). The

380 hybrid target impact performance then became governed by the HB50 performance for depths of

381 penetration $f>1 / 3$, Fig. 8. The ballistic limits of the hybrid and HB50 targets were the same,

382 Table 2. 
A XCT cross-section through the impact site of a BT10m target just above its $V_{0}$ limit is

385 shown in Fig. 14(a). The entire laminate permanently deflected in the Z-direction by outward

386 propagation of transverse hinges as depicted in Fig. 1(a). The plies below the projectile remained

387 intact. A microbuckling zone, similar to that seen with the rear-supported targets (Fig. 9), formed

388 within the failed plies adjacent to the perimeter of the projectile. In contrast to rear-supported

389 targets, delamination between plies extended several centimeters outwards from the projectile.

390 Increasing the impact velocity led to more perforated plies, which delaminated during recoil and

391 buckled as they rebounded against the side of the projectile, Fig. 14(b) and (c). The formation of

392 a shear plug was not observed at any impact velocity.

393

The HB50 laminates suffered a similar deformation and failure sequence as the impact

395 velocity was increased, Fig. 14(f). Separation of the intact plies from the failed plies within the

396 laminate was more pronounced. The ply kinks within the intact portion of the laminate are

397 thought to have occurred after peak deflection as the laminate rang-down to rest. Measurements

398 of the failed ply widths for both materials again showed the failure widths were smaller than the

399 diameter of the projectile, consistent with elastic recoil of the fiber following a tensile fracture.

400 The transverse ( $X$ - or $Y$-direction) width of the failed plies was 5 to $9 \mathrm{~mm}$.

A high-speed image sequence of the oblique front view for an edge clamped, HB50 target

403 after impact at $V_{i}=259 \mathrm{~m} \mathrm{~s}^{-1}$ is shown in Fig. 13(b). Pull-in was present behind the extensional

404 wave front, as observed with the rear-supported target impacted at a similar velocity (Fig. 13(a)),

405 but no plies had failed. Instead, the laminate transversely deflected, as observed by the base of

406 the deflection pyramid outlined in the last frame. An edge clamped HB50 target impacted above 
407 the penetration onset velocity is shown in Fig. 13(c). Evidence of ply failure is visible by $t=4.6$

$408 \mu \mathrm{s}$, and perhaps as early as $t=3 \mu \mathrm{s}$ after the start of impact.

409

410 5. Discussion

411 Ideally, the interpretation of the results would begin with a numerically study of the

412 impact process for the two materials. However, numerical assessments with even approximate

413 constitutive models are greatly complicated by the very high anisotropy present, and the many

414 length and time scales contributing to the response. Instead, we use shock propagation scaling to

415 identify the key physical aspects of the problem, and then investigate the mechanisms by which

416 penetration was facilitated in the two material systems.

\section{5.1. Onset of penetration}

418 When supported on a rigid foundation, penetration of both the HB50 and BT10m targets

419 was initiated at an impact velocity of $\sim 45 \mathrm{~ms}^{-1}$. When the impact velocity was increased to $V_{i}=$

$42075 \mathrm{~m} \mathrm{~s}^{-1}, \sim 20 \%$ of the $6 \mathrm{~mm}$ thick laminates had been penetrated. Post-mortem analysis of

421 partially perforated samples, Fig. 9(a) and (c), revealed similar damage to the samples quasi-

422 statically loaded by the same diameter hemispherical punch, Fig. 5(b) and (c). The punch

423 penetration tests also showed both materials to have similar indentation responses, with the load,

$424 F$, monotonically increasing with indentation depth, $\alpha$, until it reached a similar peak load at

425 failure in both materials, Fig. 5(a).

426 
If all of the kinetic energy from a projectile impact were converted to the work, $W$,

428 needed to overcome the material's resistance to penetration, the penetration onset velocity, $V_{0}$,

429 can be approximated from a work-energy balance,

$$
\int_{0}^{\alpha_{0}} F d \alpha=m_{p} V_{0}^{2} / 2
$$

Eq. 3

where $\alpha_{0}$ is the indentation depth at the initiation of ply failure from the punch study and

$434 m_{p}$ is the projectile mass from the impact study. This analysis is simplified by the preclusion of 435 any bending or stretching mechanisms for the rear support condition, and assumes material rate 436 effects can be neglected. After solving for $V_{0}$ in Eq. 3 and integrating the load-displacement

437 curve, Fig. 5(a), the predicted $V_{0}$ was $\sim 45 \mathrm{~m} \mathrm{~s}^{-1}$ for both materials. This is almost identical to the $438 V_{0}$ extrapolated from experimental measurements, Fig. 8(b). The impact velocity required to 439 initiate failure in the rear-supported case is therefore governed by the quasi-static work required 440 to indent the laminate, and given the similar resistance to quasi-static indentation of the two 441 materials, both had similar impact performances, Fig. 8(b).

444 penetrated, Fig. 8(b), with local failure below the projectile, Fig. 14. However, the penetration 445 onset velocity, $V_{0}$, for both materials was significantly higher than the rear supported case.

446 Furthermore, the $V_{0}$ of the HB50 laminate $\left(296 \pm 37 \mathrm{~m} \mathrm{~s}^{-1}\right)$ was substantially higher than that of

447 BT10m $\left(176 \pm 4 \mathrm{~m} \mathrm{~s}^{-1}\right)$. These differences in $V_{0}$ can be reconciled if the onset of penetration is 448 controlled by the dynamic impact pressure. 
451 launches a transient compressive shock pulse into the target, Fig. 15. The peak pressure, $P_{H}$,

452 scales as $\rho c_{T} V_{i}$, where $\rho$ is the laminate's initial density and $c_{T}$ is the laminate's through

453 thickness shock velocity (which tends to its longitudinal elastic wave speed in the weak shock

454 limit) [34]. As HB50 and BT10m have the same density and resistance to indentation failure,

455 Fig. 5(a), the impact velocity for onset of ply failure, $V_{0}$, would scale with $c_{T}{ }^{-1}$ if the dynamic

456 pressure controlled the onset of failure. The shock wave speed, $c_{T}$, for a highly shocked material

457 depends upon the stress state of a material, but will scale as $\sqrt{E_{T}}$, where $E_{T}$ is the out of plane

458 tangent modulus. For a qualitative comparison, the out of plane uniform compressive stress-

459 strain responses shown in Fig. 4(a), can be used to estimate the modulus, $E_{T}$. They give a $\sqrt{E_{T}}$

460 ratio of $\mathrm{HB} 50$ to $\mathrm{BT} 10 \mathrm{~m}$ at a strain 0.3 of $\sim 0.75$. Table 2 shows that under edge clamped loading,

$461 V_{0}$ for BT10m was lower than $\mathrm{HB} 50$, and the $V_{0}$ ratio of the materials was $\sim 0.6$; consistent with

462 the dynamic pressure governing $V_{0}$ for HB50 and BT10m when edge clamped.

Recall, this scaling of $V_{0}$ in the two materials was not observed under rear supported

465 testing, where the onset of penetration occurred at the same velocity for the two materials.

466 Furthermore, the low value of $V_{0}$ in the rear-supported case would result in insufficient shock

467 pressure to cause failure if the same mechanism were responsible for the onset of penetration in

468 the two loading scenarios (Table 2). To resolve this dichotomy, recall that in Fig. 13 the time

469 from initiation of the impact until the first ply failed was substantially greater in the rear-

470 supported case ( $9 \pm 3$ s versus 5 s for the edge clamped boundary condition). Fig. 15(a)

471 schematically illustrates propagation of a shock pulse in a laminate for the two boundary

472 conditions studied. For a rear-supported test case, the shock impedance of the steel support plate 
473 will exceed that of the target, and the compressive shock will be back reflected as a compressive

474 pulse into the laminate towards the projectile, Fig. 15(c). The pressure just beneath the projectile

475 then rises, eventually approaching the quasi-static value for contact between a rigid sphere and

476 the laminate body, Fig. 15(b). In contrast, when the shock front first reaches the rear of an edge

477 clamped target, the low inertia laminate is able to suffer an out of plane back face deflection. A

478 tensile wave is then reflected back towards the projectile, and partially relieves the shock

479 pressure, Fig. 15(d). The onset of penetration for the edge clamped target must therefore occur

480 before this reflection arrives at projectile (at $\sim 6 \mu$ s after impact for $c_{T} \approx 2 \mathrm{~mm} \mu \mathrm{s}$ ), which is

481 consistent with the high-speed observations in Fig. 13.

482

To summarize, the onset of penetration of rear-supported targets began after sufficient

484 time had elapsed for the stress to approach the quasi-static indentation limit. Consistent with

485 penetration being governed by the materials compressive strength (which is the same for HB50

486 and BT10m), the penetration onset velocity of the two materials was then the same in rear-

487 supported case. Edge clamped targets required a higher impact velocity than back supported

488 samples because the failure stress of the laminate had to be surpassed before arrival of the back

489 face reflected (tensile sign) shock pulse. Furthermore, the higher tangent modulus of the BT10m

490 material increased the maximum shock pressure at constant impact velocity resulting in a lower

$491 V_{0}$ for this material when edge clamped. The generality of these findings are likely to be affected

492 by the target thickness, given its effect upon the transit time of shock pulses that traverse the

493 sample, and by the projectile shape which governs the spatial form of the stress field.

494

495 5.2. Failure mechanisms 
The experimental observations of rear supported tested samples, Fig. 9-12, indicate that

497 the samples failed by tensile rupture of the reinforcement directly under the center of the

498 projectile, and that this occurred under the action of a through thickness compressive stress field,

499 in a loading scenario where the possibility of a membrane-stretching mode of deformation was

500 denied.

A schematic illustration of a failure process that is consistent with these previous

503 observations is given in Fig. 16. It invokes the indirect tension mechanism observed in uniform

504 compression studies in combination with a lateral displacement mechanism [30]. Fig 16(a)

505 shows the early contact situation on the $Z-Y$ plane prior to reinforcement rupture. The projectile

506 impact creates a contact stress with strongly compressive character directly beneath the

507 projectile. The anisotropic Poisson expansion of $0^{\circ}$ plies in the $Y$-direction loads the $90^{\circ}$ plies in

508 tension, and vice versa, with the highest tensile stress occurring in the $90^{\circ}$ ply closest to the

509 projectile. When this $90^{\circ}$ ply fails in indirect tension, Fig. 16(b), the ply recoils from the fracture

510 site, and the projectile is able to advance into the sample, but with a velocity reduced by the work

511 done in advancing a ply thickness against the compressive resistance of the material. The

512 eventual rebound of the fractured ply results in a series of buckles forming to accommodate the

513 length of ply impeded by the projectile's presence (half cord length at the original ply depth).

An alternate mechanism that could have activated tensile rupture would have been if the

516 extensional strain required of the plies to conform to the contact length of the projectile, Fig.

517 16(a), reached the failure strain of the ply $(\sim 2 \%)$. Since failure initiation under both quasi-static

518 loading and impact loadings were the same when rear supported, we examine the quasi-static 
519 penetration case, which failed after $1.5 \mathrm{~mm}$ of indentation, Fig. 5(a). This corresponds to a

520 projected loading area of $8.2 \mathrm{~mm}$ and an increase in the length of the reinforcement under the

521 projectile of $0.7 \mathrm{~mm}$. The reinforcement, however, is likely to be pulled inwards, towards the

522 projectile contact surface from outside the loading area since the interlaminar shear strength is so

523 low, Table 1. For HB50, the load sustained by shear per projectile unit width is $35 \mathrm{~N} / \mathrm{mm}$, while

$524110 \mathrm{~N} / \mathrm{mm}$ would be needed to reach the ply failure strength (1.7 GPa). Therefore, reinforcement

525 will pull in to relieve the strain regardless of indentation depth. Furthermore, the lower ply

526 strength and higher shear strength of BT10m would result in a lower penetration resistance than

527 for HB50. The identical penetration versus impact velocity response of back-supported HB50

528 and BT10m materials hence suggests penetration is controlled by the laminate compressive

529 strength and not the ply tensile strength.

Since the plies below the sides of the projectile contact surface do not reach as high of a

532 pressure, they do not undergo indirect tension failure. Instead, as schematically illustrated in Fig.

533 16(b) and (c) and observed experimentally in Fig. 10(c), they are laterally displaced in a manner

534 analogous to that observed during ductile hole enlargement in some metals; though here material

535 displacement required ply splitting and delamination, as observed with the -XCT technique. It

536 has been argued that reinforcement slip lowers a laminate's resistance to penetration [30]. This

537 may also be the case here since penetration by indirect tension requires application of a stress

538 comparable to the reinforcement strength (of order $1 \mathrm{GPa}$ ) while lateral displacement is matrix

539 strength controlled and can be activated with a stress of a few MPa (a $10^{3}$-fold difference). 
Examination of the edge clamped targets, Fig. 14, indicated two mechanisms of response.

542 Initially, projectile penetration occurred by tensile rupture of plies directly beneath the nose of

543 the projectile in combination with lateral displacement near the edges of the projectile. The

544 experimental observations of this process, Fig. 14(a) to (c) and (f), were consistent with the

545 mechanism observed in a back supported test scenario. However, unlike the rear-supported tests,

546 the unfailed portion of partially perforated laminates suffered large out of laminate plane

547 deflections and had delaminated from the perforated part of the laminate. A schematic

548 illustration of the proposed failure mechanisms are shown in Fig. 17. Upon initial impact, Fig.

549 17(a), the dynamic pressure promptly induces indirect tension fracture of plies directly beneath

550 the center of the contact surface). Once the compressive shock pulse had propagated across the

551 sample, Fig. 16(d), the laminate could begin to move, and the pressure exerted by the projectile

552 then drops because of the work it had performed to penetrate the first plies, and because the

553 impact velocity in the local laminate frame of reference began to decrease due laminate

554 acceleration. As the intact (1-f) fraction of the laminate continued to deflect, a membrane stress

555 developed within it. The work done in extending the laminate against the membrane stretching

556 resistance could then further retard the projectile motion. It is noted that during the projectile

557 arrest phase, a local contact and membrane stress exists, and the combined stress may have

558 enabled additional penetration during laminate deflection, Fig. 17(b).

560 The edge clamped hybrid target, with the front third of the target thickness consisting of

561 BT10m and the remainder HB50, had the same ply perforation onset velocity, $V_{0}$, as BT10m,

562 Fig. 8(b). This is consistent with $V_{0}$ being governed by the dynamic impact pressure. After

563 penetrating the BT10m portion of the hybrid, the depth of penetration followed the same 
564 dependence with impact velocity as the higher performance HB50 target. These results suggest

565 that a benefit may exist to a multi-material composite lamination, and several groups have

566 investigated multi-material composite concepts [35-39]. The present study suggests the

567 placement of plies with the lowest impedance and the greatest resistance to indirect tension

568 (compressive strength) nearest the impact side, where deflection is minimal, would be beneficial.

569 The higher tensile strength plies would be placed nearest the rear side of a laminate to sustain

570 higher membrane stresses. It is also interesting to note that for some projectile nose geometries,

571 use of a material with too weak of an inter-laminar shear strength may result in low ballistic

572 resistance with failure dominated by lateral ply displacement.

573

\section{6. Concluding remarks}

An investigation of the deformation and fracture mechanisms that accommodate

576 progressive projectile penetration of $\left[0^{\circ} / 90^{\circ}\right]$ UHMWPE reinforced plastic composites has been

577 performed. The study exploited differences in the response of HB50 fiber- and BT10 tape-

578 reinforced grades of Dyneema ${ }^{\circledR}$. The HB50 and BT10m laminates had similar transverse (out-of-

579 plane) compressive strengths, while HB50 had a 40\% higher ply tensile strength. Ballistic

580 targets, measuring $6 \mathrm{~mm}$ in thickness, were made from each material as well as from a bilayer

581 hybrid, where the front third of the thickness was BT10m. The impact of each target by a 12.7

$582 \mathrm{~mm}$ diameter, hardened (non-deforming) sphere was examined in test scenarios where the target

583 was either supported on a stiff foundation to prevent transverse deflection or clamped along its

584 edges to permit out of plane deflection. 
When rear supported, the velocity needed to initiate penetration and the dependence of

587 the depth of penetration upon impact velocity were the same for the two materials consistent

588 with material compressive response governing penetration. Indirect tension of the reinforcement

589 and lateral displacement of material from the tip of the projectile accommodated penetration. No

590 shear plug mechanism was observed with either material.

When end supported, both materials had a higher penetration onset velocity and a higher

593 impact performance compared to the back supported test case. The velocity of penetration

594 initiation scaled inversely with shock pulse speed (HB50 required a higher velocity to initiate ply

595 failure than BT10m); while the ballistic limit increased with the tensile strength of the material.

596 The samples exhibited progressive failure as the impact velocity increased, and failure was

597 initiated rapidly before shock pulse reflections from the back face reached the region of contact.

598 The mechanism of progressive penetration was consistent with indirect tension failure in

599 combination with lateral displacement at the sides of the projectile and membrane stretching of

600 the unfailed portion of the laminate. These observations suggest future investigation of multi-

601 material (hybrid) laminates that combine materials with highest compressive strength and lowest

602 impendence near the impact site and those with highest tensile strength at the rear may result in

603 significant impact performance benefits.

604

\section{Acknowledgements}

606 We are grateful to DSM for providing the materials used in this study. This research was

607 funded by the Defense Advanced Research Projects Agency (DARPA) under grant number

608 W91CRB-11-1-0005 (Program manager, Dr. J. Goldwasser). Dyneema ${ }^{\circledR}$ is a trademark of DSM. 


\section{References}

611 [1] Cunniff PM. Dimensionless parameters for optimization of textile-based body armor

612 systems. In: Reinecke WG, editor. Proc. 18th Int. Symp. Ballist., San Antonio, TX:

613 Technomic Publishing Company, Inc; 1999, p. 1303-10.

614 [2] Cheeseman BA, Bogetti TA. Ballistic impact into fabric and compliant composite

615 laminates. Compos Struct 2003;61:161-73. doi:10.1016/S0263-8223(03)00029-1.

616 [3] Cunniff PM. An analysis of the system effects in woven fabrics under ballistic impact. Text $617 \quad$ Res J 1992;62:495-509.

618 [4] Phoenix SL, Porwal PK. A new membrane model for the ballistic impact response and V50 619 performance of multi-ply fibrous systems. Int J Solids Struct 2003;40:6723-65.

620 doi:10.1016/S0020-7683(03)00329-9.

621 [5] Chocron S, King N, Bigger R, Walker JD, Heisserer U, van der Werff H. Impacts and 622 Waves in Dyneema® HB80 Strips and Laminates. J Appl Mech 2013;80:031806-1 - 10. 623 doi:10.1115/1.4023349.

624 [6] Smith JC, Fenstermaker CA, Shouse PJ. Behavior of Filamentous Materials Subjected to 625 High-Speed Tensile Impact. Symp. Dyn. Behav. Mater., West Conshohocken, PA: ASTM $626 \quad$ International; 1963, p. 47-69.

627 [7] Christensen RM. Mechanics of Composite Materials. New York: Wiley; 1979.

628 [8] O’Masta MR, Deshpande VS, Wadley HNG. Mechanisms of projectile penetration in 629 Dyneema ${ }^{\circledR}$ encapsulated aluminum structures. Int J Impact Eng 2014;74:16-35. 630 doi:10.1016/j.ijimpeng.2014.02.002. 
631 [9] Iremonger MJ. Polyethylene composites for protection against high velocity small arms bullets. In: Reinecke WG, editor. Proc. 18th Int. Symp. Ballist., San Antonio, TX: 1999, p.

634 [10] Greenhalgh ES, Bloodworth VM, Iannucci L, Pope D. Fractographic observations on Dyneema ${ }^{\circledR}$ composites under ballistic impact. Compos Part Appl Sci Manuf 2013;44:5162. doi:10.1016/j.compositesa.2012.08.012.

[11] Heisserer U, van der Werff H, Hendrix J. Ballistic Depth of Penetration Studies in Dyneema ${ }^{\circledR}$ Composites. In: Wickert M, Salk M, editors. Proc. 27th Int. Symp. Ballist., vol. 2, Freiburg, Germany: DEStech Publications, Inc.; 2013, p. 1936-43.

[13] Karthikeyan K, Russell BP. Polyethylene Ballistic Laminates: failure mechanics and on the ballistic performance of ultra high molecular weight polyethylene composite. Int J Impact Eng 2015;75:174-83. doi:10.1016/j.ijimpeng.2014.07.008.

[15] Cantwell WJ, Morton J. Impact perforation of carbon fibre reinforced plastic. Compos Sci Technol 1990;38:119-41. doi:10.1016/0266-3538(90)90002-M.

[16] Culnane AH, Woodward RL, Egglestone GT. Failure examination of composite materials using standard metallographic techniques. J Mater Sci Lett 1991;10:333-4. doi:10.1007/BF00719700. 
653 [17] Lee S-WR, Sun CT. Dynamic penetration of graphite/epoxy laminates impacted by a blunt654 ended projectile. Compos Sci Technol 1993;49:369-80. doi:10.1016/0266-3538(93)90069S.

656 [18] Gama BA, Gillespie Jr. JW. Punch shear based penetration model of ballistic impact of thick-section composites. Compos Struct 2008;86:356-69. doi:10.1016/j.compstruct.2007.11.001.

[19] Gama BA, Gillespie Jr. JW. Finite element modeling of impact, damage evolution and penetration of thick-section composites. Int J Impact Eng 2011;38:181-97.

[20] Shaktivesh, Nair NS, Sesha Kumar CV, Naik NK. Ballistic impact performance of doi:10.1016/j.ijimpeng.2010.11.001. composite targets. Mater Des 2013;51:833-46. doi:10.1016/j.matdes.2013.04.093.

[21] Ming-Yuan H, Hutchinson JW. Crack deflection at an interface between dissimilar elastic materials. Int J Solids Struct 1989;25:1053-67. doi:10.1016/0020-7683(89)90021-8.

[22] Noselli G, Deshpande VS, Fleck NA. An analysis of competing toughening mechanisms in layered and particulate solids. Int J Fract 2013;183:241-58. doi:10.1007/s10704-013-98908.

[23] Karthikeyan K, Russell BP, Fleck NA, O’Masta MR, Wadley HNG, Deshpande VS. The soft impact response of composite laminate beams. Int J Impact Eng 2013;60:24-36. doi:10.1016/j.ijimpeng.2013.04.002.

[24] O’Masta MR, Compton BG, Gamble EA, Zok FW, Deshpande VS, Wadley HNG. Ballistic impact response of an UHMWPE fiber reinforced laminate encasing an aluminum-alumina hybrid panel. Int J Impact Eng 2014:[Submitted for publication]. 
675 [25] Attwood JP, Khaderi SN, Karthikeyan K, Fleck NA, O’Masta MR, Wadley HNG, et al. The

676 out-of-plane compressive response of composites. J Mech Phys Solids n.d.

$677 \quad$ doi:10.1016/j.jmps.2014.05.017.

678 [26] O’Masta MR, Deshpande VS, Wadley HNG. Defect controlled transverse compressive

679 strength of polyethylene fiber laminates. Int J Solids Struct 2015;52:130-49.

$680 \quad$ doi:10.1016/j.ijsolstr.2014.09.023.

681 [27] Chocron S, Nicholls AE, Brill A, Malka A, Namir T, Havazelet D, et al. Modeling

682 unidirectional composites by bundling fibers into strips with experimental determination of

683 shear and compression properties at high pressures. Compos Sci Technol 2014;101:32-40.

684 doi:10.1016/j.compscitech.2014.06.016.

685 [28] Backman ME, Goldsmith W. The mechanics of penetration of projectiles into targets. Int J

686 Eng Sci 1978;16:1-99. doi:10.1016/0020-7225(78)90002-2.

687 [29] Corbett GG, Reid SR, Johnson W. Impact loading of plates and shells by free-flying

688 projectiles: A review. Int J Impact Eng 1996;18:141-230. doi:10.1016/0734-

$689 \quad 743 \times(95) 00023-4$.

690 [30] Lee BL, Walsh TF, Won ST, Patts HM, Song JW, Mayer AH. Penetration Failure

691 Mechanisms of Armor-Grade Fiber Composites under Impact. J Compos Mater

692 2001;35:1605-33. doi:10.1106/YRBH-JGT9-U6PT-L555.

693 [31] Harding KC, Mitchell JE, Petrea WB. High modulus ultra high molecular weight

694 polyethylene tape. US8206810 B1, 2012.

695 [32] Morye SS, Hine PJ, Duckett RA, Carr DJ, Ward IM. A comparison of the properties of hot

696 compacted gel-spun polyethylene fibre composites with conventional gel-spun polyethylene 
fibre composites. Compos Part Appl Sci Manuf 1999;30:649-60. doi:10.1016/S1359835X(98)00175-4.

699 [33] Russell BP, Karthikeyan K, Deshpande VS, Fleck NA. The high strain rate response of 700 Ultra High Molecular-weight Polyethylene: From fibre to laminate. Int J Impact Eng $701 \quad 2013 ; 60: 1-9$. doi:10.1016/j.ijimpeng.2013.03.010.

702 [34] Ahrens TJ. Equation of State. In: Asay JR, Shahinpoor M, editors. High-Press. Shock Compression Solids, NY: Springer-Verlag; 1993, p. 75-114.

704 [35] Cunniff PM. Decoupled response of textile body armor. Proc. 18th Int. Symp. Ballist., San Antonio, TX: 1999, p. 814-21.

[36] Larsson F, Svensson L. Carbon, polyethylene and PBO hybrid fibre composites for structural lightweight armour. Compos Part Appl Sci Manuf 2002;33:221-31. doi:10.1016/S1359-835X(01)00095-1.

[37] Lyons FS, Mears JA, Weedon GC, Harding KC, Owen L, Russell PA, et al. Ballisticresistant article including one or more layers of cross-plied uhmwpe tape in combination with cross-plied fibers. US7972679 B1, 2011.

[38] Lyons FS, Mears JA, Weedon GC, Harding KC, Owen L, Russell PA, et al. Ballisticresistant panel including high modulus ultra high molecular weight polyethylene tape. Thermoplastic Laminates. Aberdeen Proving Ground, MD: Army Research Laboratory; 2011. 
Figure 1. Schematic illustrations of the response of (a) thin and (b) thick $\left[0^{\circ} / 90^{\circ}\right]$ laminates following impact by a spherical non-deforming projectile. Progressive failure of a thick laminate occurs by (c) shear plugging or (d) indirect tensile failure of the fibers due to anisotropic Poisson expansion of adjacent plies in a compressed $\left[0^{\circ} / 90^{\circ}\right]$ laminate (e) or (f) lateral displacement of the reinforcement.

Figure 2. Optical micrographs of the $X-Z$ plane cross-sections of (a) an HB50 and (b) a BT10m consolidated laminate.

Figure 3. Schematic illustration of the fabrication of the BT10m edge clamped sample: (a) The as-received BT10 grade plain woven tape was peeled apart into its constituent single ply tapes; (b) the tapes were layered to form a $\left[0^{\circ} / 90^{\circ}\right]_{72}$ lay-up; (c) after hot consolidation, tabs used to maintain alignment were removed.

Figure 4. (a) Uniform compressive stress versus strain responses for $L=12 \mathrm{~mm}$ BT10m tape and HB50 fibrous laminates with $\left[0^{\circ} / 90^{\circ}\right]$ lay-up orientations. (b) The variation of the uniform compressive strength, $\sigma_{c}$, with in-plane sample length, $L$, for the two laminates.

Figure 5. (a) The indentation load, $F$, as a function of indentation depth, $\alpha$, when a $12.7 \mathrm{~mm}$ diameter sphere was pushed into a rear supported laminate. Optical micrographs of crosssectioned HB50 (b) and BT10m (c) samples loaded to $\alpha \approx 2 \mathrm{~mm}$. 
Figure 6. Schematic illustrations of $\left[0^{\circ} / 90^{\circ}\right]$ laminated target plates situated for an impact while either (a) rear supported or (b) edge clamped.

Figure 7. Schematic illustration of the steel sphere impact experiment using an edge clamped sample geometry.

Figure 8. (a) The residual velocity, $V_{r}$, and (b) the perforated laminate fraction, $f$, are plotted as functions of the impact velocity, $V_{i}$, for both rear supported and edge clamped targets for the two materials and the hybrid system. Solid lines are drawn to help reveal trends.

Figure 9. Optical micrographs of cross-sectioned, rear supported targets. Micrographs (a) and (b) correspond to HB50 targets impacted at $75 \mathrm{~m} \mathrm{~s}^{-1}$ and $149 \mathrm{~m} \mathrm{~s}^{-1}$, respectively, while (c) and (d) correspond to BT10m targets impacted at $84 \mathrm{~m} \mathrm{~s}^{-1}$ and $152 \mathrm{~m} \mathrm{~s}^{-1}$, respectively. All micrographs are at the same magnification.

Figure 10. (a-c) Orthogonal micro-XCT reconstructed cross-sections of a rear supported, HB50 target after impact at $V_{i}=117 \mathrm{~m} \mathrm{~s}^{-1}$. Section planes are identified in (d). 
Figure 11. Micro-XCT reconstructed cross-section of a rear supported, BT10m target after impact at $V_{i}=115 \mathrm{~m} \mathrm{~s}^{-1}$.

Figure 12. (a) Photograph of in-plane $(X-Y)$ section of a ply $\left(u_{z}=-0.24 \mathrm{~mm}\right)$ peeled from a rear supported, HB50 target after impact at $V_{i}=143 \mathrm{~m} \mathrm{~s}^{-1} .(+) Z$ is into page. (b) Schematic illustration used to define the crater and failure widths. (c) The measured widths are plotted as functions of the original $Z$-position, $u_{z}$, relative to the target's impact surface.

Figure 13. High speed image sequences showing the oblique front view of the following three HB50 targets: (a) rear supported and impacted at $225 \mathrm{~m} \mathrm{~s}^{-1}$, and edge clamped and impacted at either (b) $260 \mathrm{~m} \mathrm{~s}^{-1}$ or (c) $505 \mathrm{~m} \mathrm{~s}^{-1}$. Grid lines are spaced $5 \mathrm{~mm}$ apart and are aligned with the $\left[0^{\circ} / 90^{\circ}\right]$ ply orientations.

Figure 14. XCT reconstructed cross-sections of edge clamped (a-c) BT10m, (d-e) hybrid and (f) HB50 targets.

Fig 15. Schematic illustrations of laminate impact by a non-deforming spherical projectile. (a) A transient pressure wave with amplitude $P_{H}$ is launched into the laminate. (b) A contact stress, $P_{S}$, is formed near the laminate surface. (c) Reflection of the compressive shock at a laminate - rigid 
foundation interface doubles the pressure of the reflected compression shock. (d) Reflection at the rear of the edge clamped laminate results in a sign change (compression to tension) to the pressure pulse.

Figure 16. (a) Ply failure and lateral displacement beneath the contact region are necessary to facilitate projectile penetration. (b) The compressive stress imposed by the projectile indirectly loads the plies in tension causing ply tensile failure, lateral recoil and rebound against the projectile. Penetration is also accompanied by local delamination, ply thickening and laminate bulging after laminate penetration. (c) A schematic illustration showing the region of $X$-direction fiber fracture, micro-buckling of the rebounded ply and $Y$-direction ply displacement at the sides of the contact.

Fig 17. Penetration mechanisms of an edge clamped target. (a) The case shortly after initial impact before shock reflection at the rear face. (b) Shows the situation after the shock pulse has traversed the laminate and the intact portion suffers out of plane deflection that is resisted by membrane stretching. 
Figure 1

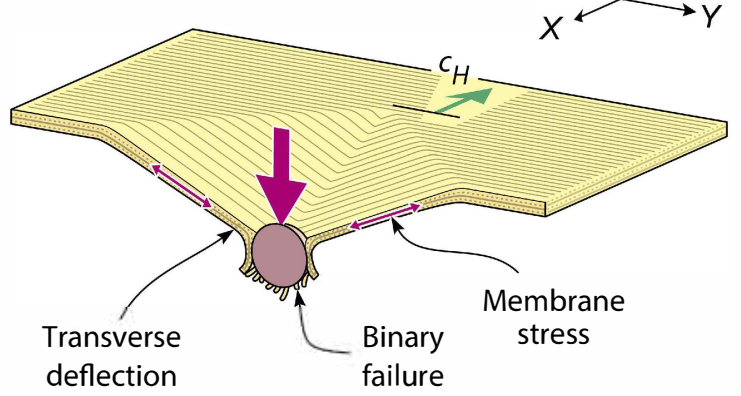

(c) Shear plugging

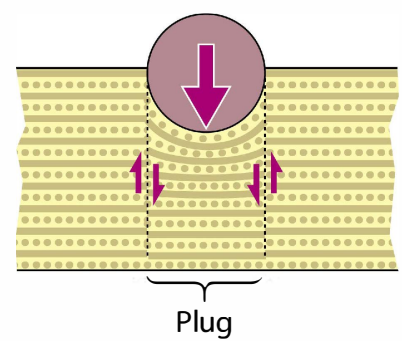

(d) Indirect tension

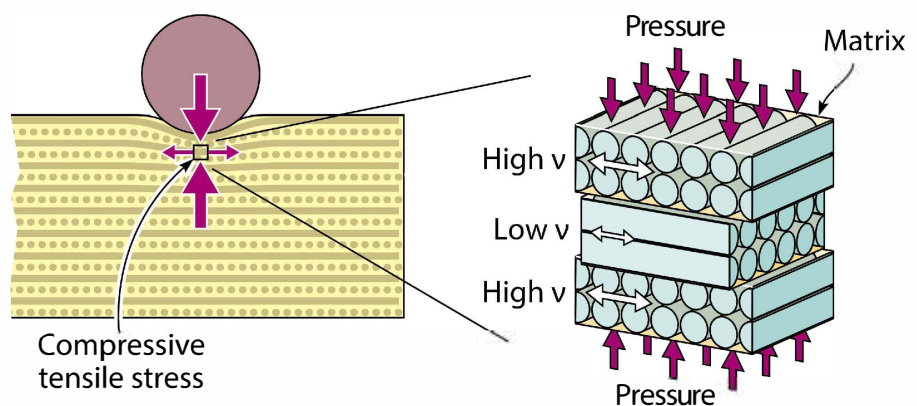

(e) Poisson expansion

Pressure

(f) Lateral displacement

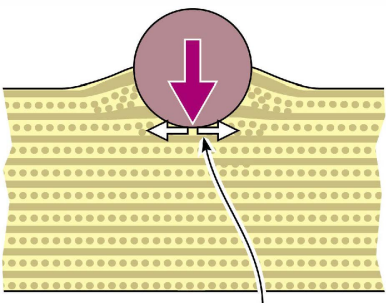

Lateral reinfocement displacement 


\section{Figure 3}

2 adpered sets of $0^{\circ} / 90^{\circ}$ plain weave

(c)
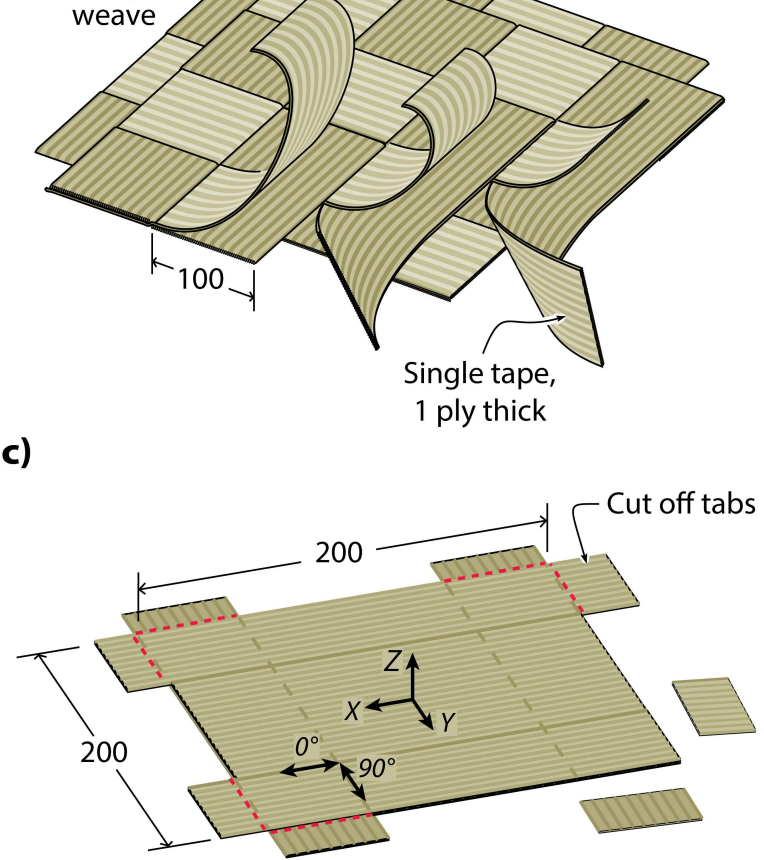

1 ply thick

\section{(a)}

(b)
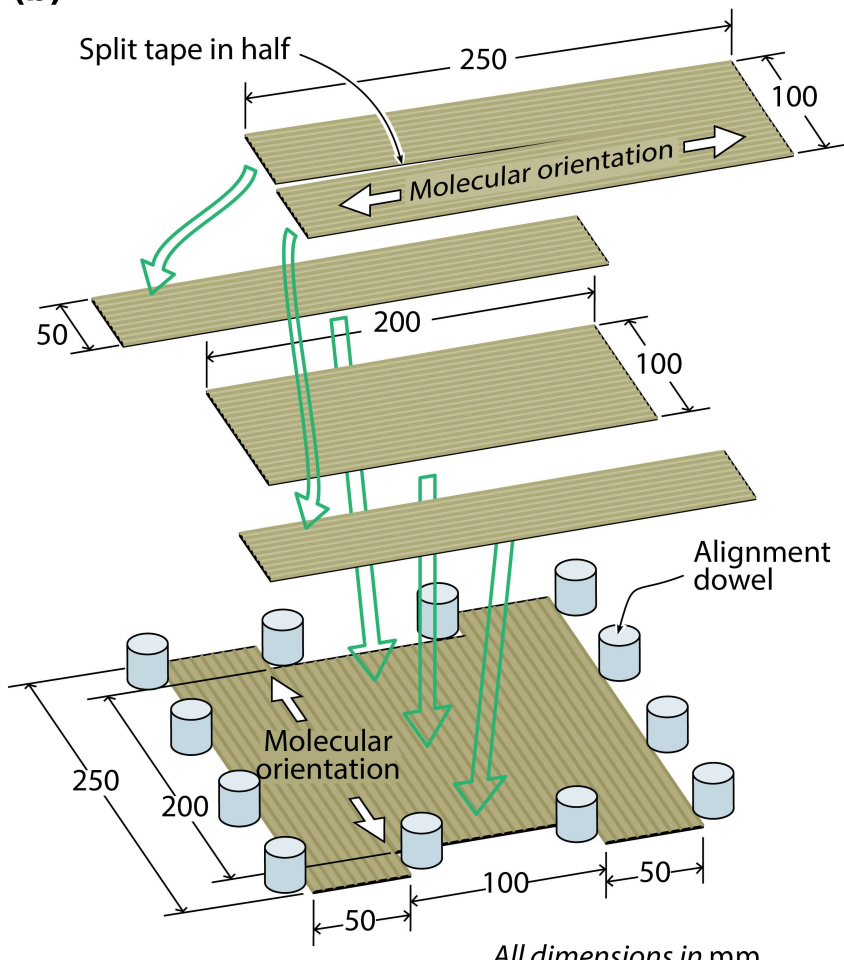


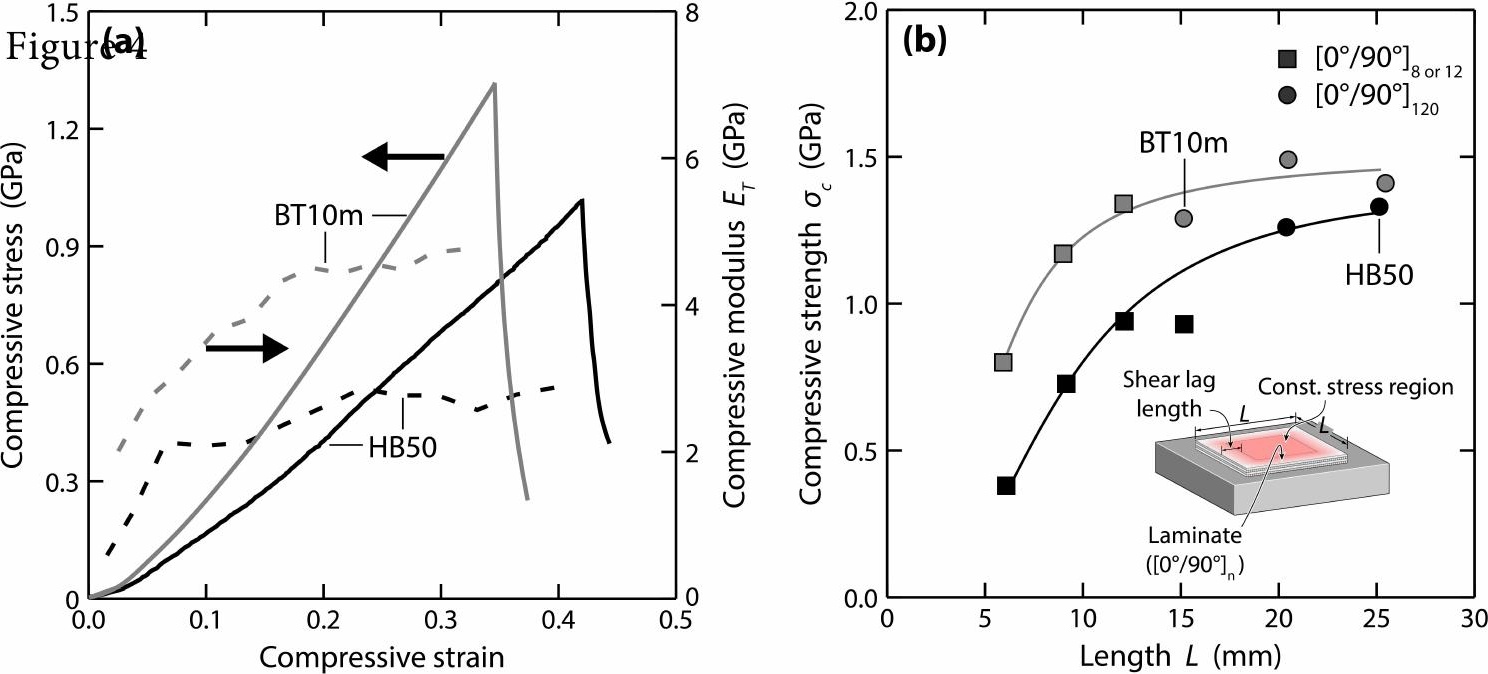


(a) Rear supported

Front view

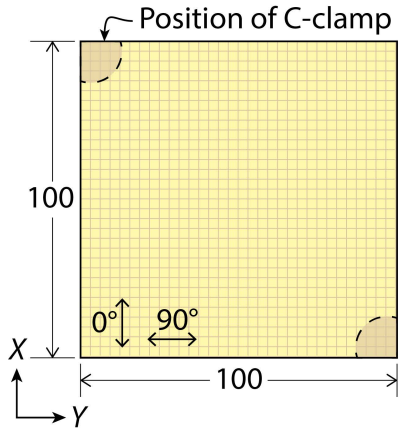

\section{(b) Edge clamped}

Rear view

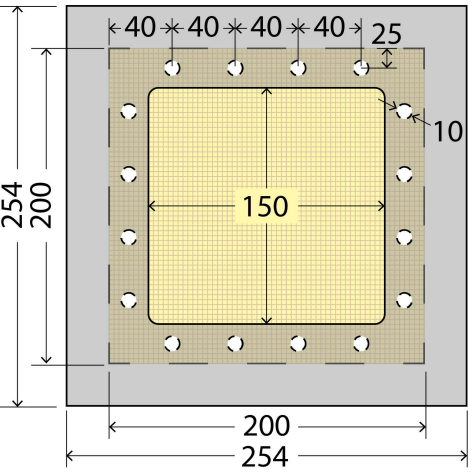

All dimensions are in $\mathrm{mm}$
Profile Figure 6

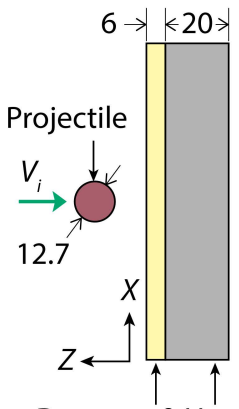

Dyneema ${ }^{\circledR}$ Hardened laminate A2 steel

Profile view

Dyneema $^{\circledR}$ laminate

16 bolts with nuts $\rightarrow \in-6$

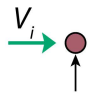

Projectile

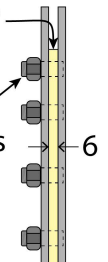

5

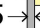

$\rightarrow 5$

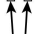

Steel

plates 
Paper break screens

Sabot stripper

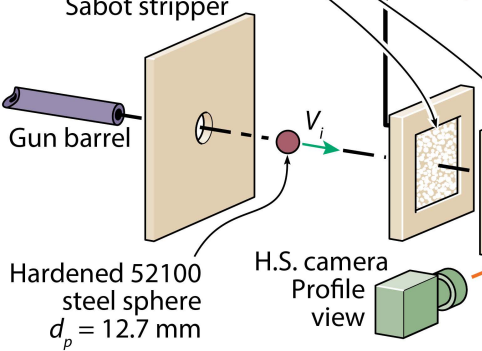

H.S. camera Oblique front view

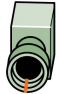

I
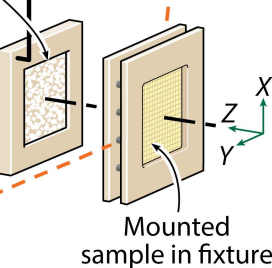


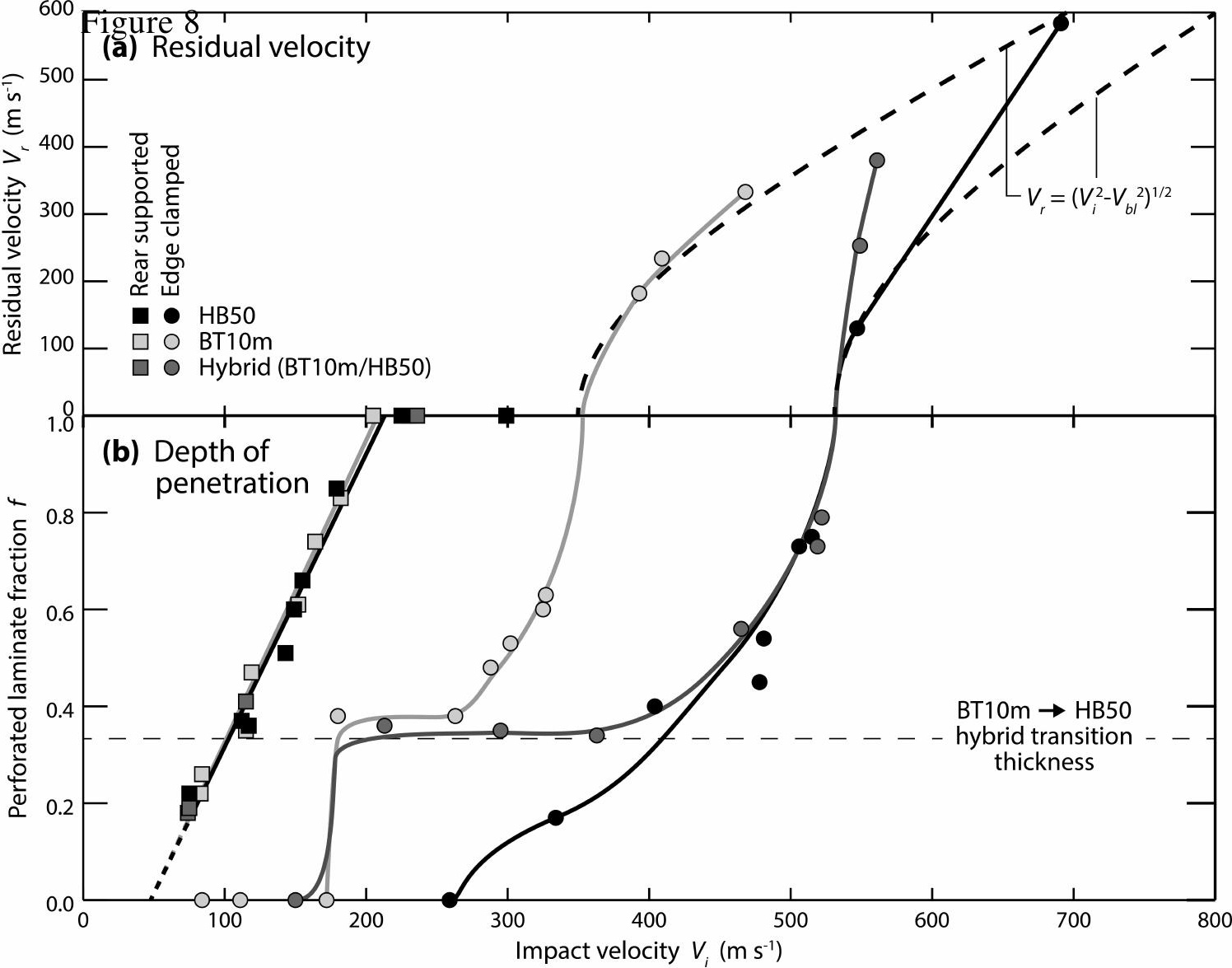


Fioure 9

(a) $V_{i}=75 \mathrm{~m} \mathrm{~s}^{-1} \begin{aligned} & \text { Buckling \& } \\ & \text { bulging zone }\end{aligned}$

HB50

BT10m
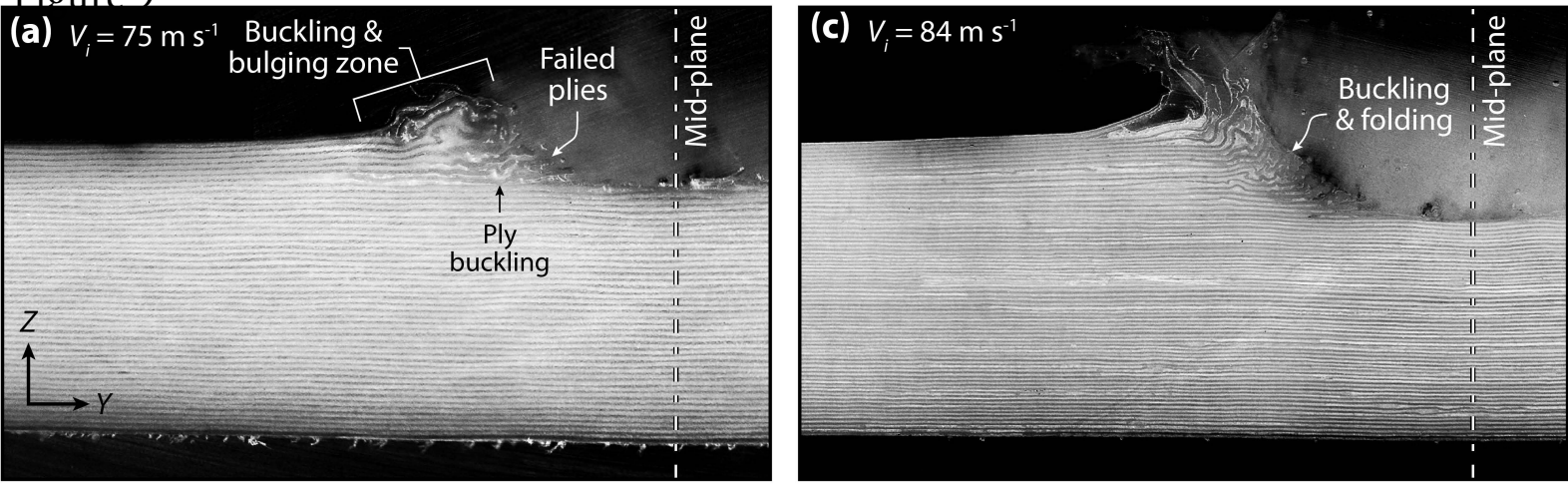

(b) $v_{i}=149 \mathrm{~m} \mathrm{~s}^{-1}$
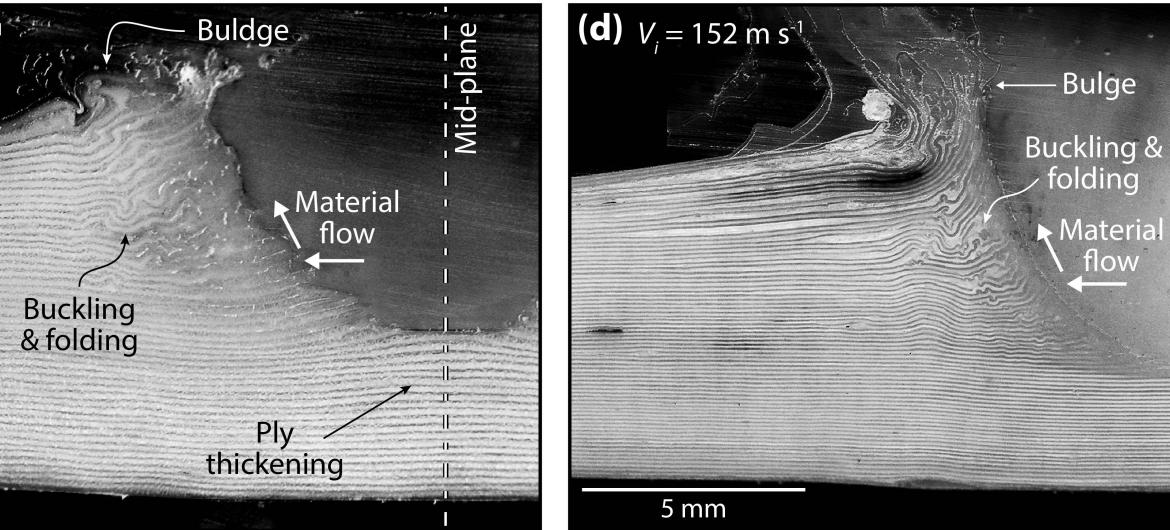

$1 \frac{\mathrm{d}}{1}$

$1 \frac{0}{0}$ 
$u_{z}=-0.24 \mathrm{~mm}$

Failed fiber
Ply splitting

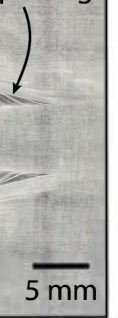

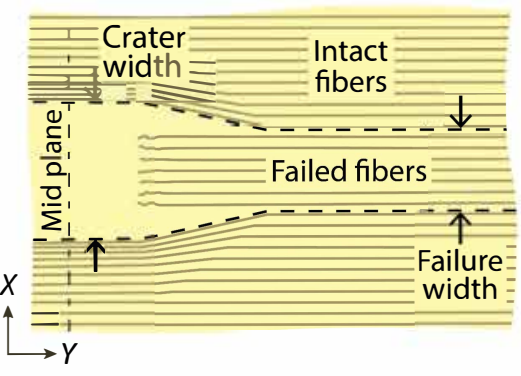

(c)

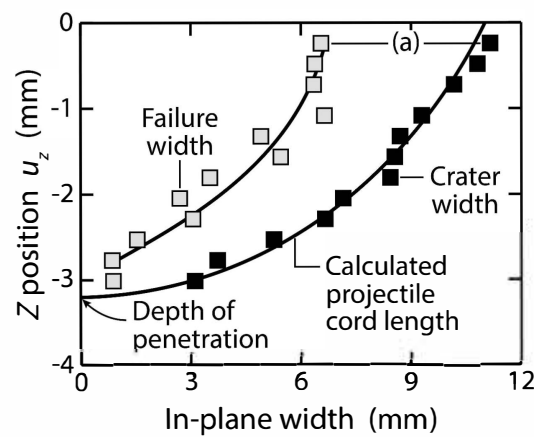


(a) Figure 15V $\Rightarrow$ (b)
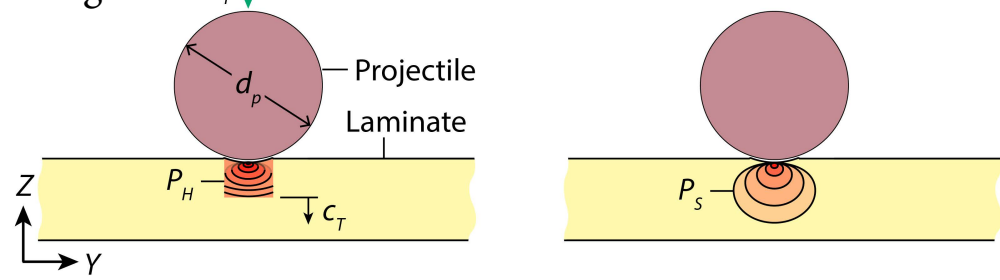

(c)

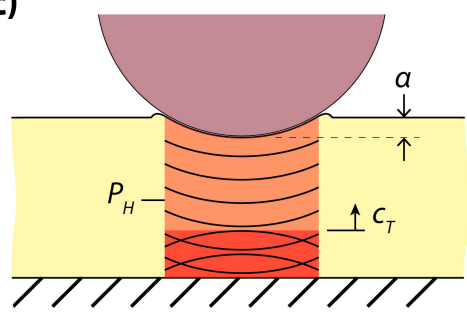

(d)

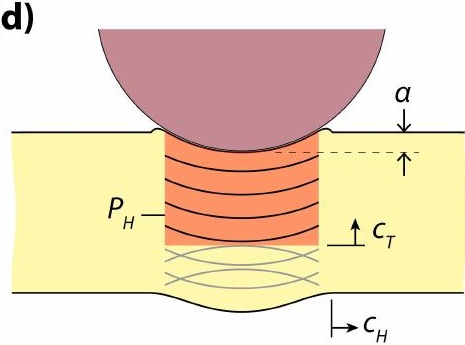


